\title{
A preliminary assessment of consumer's exposure to pesticide residues in fisheries products
}

\author{
F. Sun ${ }^{\mathrm{a}, \mathrm{b}, *}$, S.S. Wong ${ }^{\mathrm{b}}$, G.C. Li ${ }^{\mathrm{b}}$, S.N. Chen ${ }^{\mathrm{c}}$ \\ ${ }^{a}$ Institute of Zoology, National Taiwan University, No. 1, Sec. 4, Roosevelt Road, Taipei, Taiwan, ROC \\ ${ }^{\mathrm{b}}$ Department of Residual Control, Taiwan Agricultural Chemicals and Toxic Substance Research Institute, \\ Council of Agriculture, 11 Kung-Ming Rd., Wufeng, Taichung Hsien 413, Taiwan, ROC \\ ${ }^{c}$ Institute of Fisheries Science, National Taiwan University, No. 1, Sec. 4, Roosevelt Road, Taipei, Taiwan, ROC
}

Received 8 July 2004; received in revised form 22 April 2005; accepted 29 April 2005

Available online 29 June 2005

\begin{abstract}
The fisheries products in this study comprise fish, bivalve, crustacean and cephalopod collected from different types of markets in Taiwan between the years 2001 and 2003. A total of 91 pesticide residues belonging to four major pesticide groups were tested and analyzed. The test results show that $65.40 \%$ of fish, $93.55 \%$ of shellfish, $84.92 \%$ of crustacean and $98.33 \%$ of cephalopod samples contain no detectable residues. There are only two kinds (organochlorine and organophosphate) of totally six pesticides (DDTs, dieldrin, chlorpyrifos, fenitrotion, fenthion and prothion) that have been detected from the fisheries products in this study. For there were pesticides present in the fish products, consumption of fisheries product there was no zero risk. But the exposure of consumer did not exceed the acceptable daily intakes (ADI). For male, there was the highest risk in exposure to dieldrin, which the percentage of ADI was $93.56 \%$. This study also suggests that a yearly monitoring program for organophosphate pesticide residues in fish is necessity. (C) 2005 Elsevier Ltd. All rights reserved.
\end{abstract}

Keywords: Seafood; Pesticide residues; Estimated dietary intakes; Risk assessment

\section{Introduction}

A number of pesticides have been identified as likely to cause disturbance to natural hormones in our bodies. Unfortunately, they are commonly found in our food, such as fish. Consumption of contaminated

\footnotetext{
* Corresponding author. Address: Department of Residual Control, Taiwan Agricultural Chemicals and Toxic Substance Research Institute, Council of Agriculture, 11 Kung-Ming Rd., Wufeng, Taichung Hsien 413, Taiwan, ROC. Tel.: +886 4 23302101x409; fax: +886423324738

E-mail address: sunfeei@tactri.gov.tw (F. Sun).
}

fisheries products could be a serious risk to human (Keith, 1998).

Pesticides are widely used in agriculture and sanitation for defense of pests. Some of them are also used in aquaculture. Both agriculture and aquaculture are traditional economy activity in Taiwan. Monitoring of pesticide residues in vegetables and fruits has been conducted since 1985 in Taiwan (Li, 2000). However, data of civilian exposure to pesticides through fish ingestion are scanty. Only a few reports on monitoring of organochlorine pesticide residues in Taiwan fish can be found in the literature (Ling and Huang, 1995). Fisheries products is very popular in the Taiwanese cuisine. The major raw materials include fish, crab, shrimp, bivalve and 
cephalopod, of which most growing history was unknown. Pesticide residues in fisheries products should be of great concern to consumers.

There are four major groups of pesticides in agricultural activities in the history of pesticide use. Organochlorine (OC) pesticides could persist in the environment for several years and subsequently accumulate in aquatic organisms. Since 1940s, OC pesticides have become the routine chemicals in environmental monitoring program (Neidermyer and Hickey, 1976). At present, three other kinds of pesticides, organophosphate (OP), pyrethroids and carbamate, have been largely used to replace OCs in agricultural activities. Untowardly, their moderate persistence, toxicity and bioaccumulation ability in aquatic organisms have been noticed (Sreenivasula et al., 1983; Lenardon et al., 1984; Hanazato, 1991; Fairchild et al., 1992; Sreenivasula, 1992; Gupta, 1994; Gomez et al., 1995; Serrano et al., 1995; Saglio et al., 1996; Singh and Sharma, 1998; Lutnicka et al., 1999). The objective of this investigation is to determine the concentration levels of pesticide residues in edible parts of consumed fisheries products in the market. The data enable us to estimate pesticide dietary intakes in citizen and to compare them with acceptable daily intakes (ADIs) of the Food and Agricultural Organization (FAO) as well as with the World Health Organization (WHO), so as to assess potential health hazards.

\section{Materials and methods}

\subsection{Pesticide standard}

A total of 91 pesticides belonging to four major pesticide groups were tested in this study (Table 1). There were purchased from Dr. Ehrenstorfer GmbH, Merck or Riedel-deHaen, separately (Table 1). The purity of all pesticide standards was over $95 \%$ except cyfluthrin (94.50\%), demeton-S-methyl (94\%), permethrin $(92 \%)$, phenthoate $(92 \%)$, phorate $(88 \%)$, pyraclofos $(91.6 \%)$, tokuoxon (91\%), tralomrthrin $(93.50 \%)$ and triazophos $(70 \%)$. These pesticides were divided into nine groups according to their chromatograph in gas chromatography (GC) and high-performance liquid chromatography (HPLC).

Table 1

Pesticides tested

\begin{tabular}{|c|c|}
\hline Kinds/grouping & Pesticide and its metabolites (factory) ${ }^{\mathrm{a}}$ \\
\hline $\begin{array}{l}\text { Carbamate: } 20 \\
\text { Group 1: }\end{array}$ & $\begin{array}{l}\text { Aldicarb (3); Aldlicarb sulfoxide (3); Carbaryl (3); Carbofuran (3); } \\
\text { Carbofuran-3-hydroxy (1); Fenobucarb (1); Isoprocarb (1); Metolcarb (3); Oxamyl (1); Thiodicarb (1) }\end{array}$ \\
\hline Group 2: & $\begin{array}{l}\text { 1-Naphthol (3); Aldicarb sulfone (3); Bendiocarb (1); Butocarboxim (3); } \\
\text { Carbofuran-3-keto (1); Macbal (1); Methiocarb (3); Methomyl (3); Promecarb (3); Propoxur (1) }\end{array}$ \\
\hline
\end{tabular}

Organochlorine and nitrogen-containing pesticides: 14

Group 3: $\quad$ Alachlor (1); Aldrin (1); Chlorobenzilate (1); $p, p^{\prime}$-DDE (1); $p, p^{\prime}$-DDT (1);

Dieldrin (1); Endosulfan (3); Endosulfan sulfate (3); Endrin (1); Heptachlor (3);

Heptachlor epoxide (3); Lindane (1); Methoxychlor (3); Trifluralin (1)

Organophosphate: 41

Group 4: $\quad$ Bromophos-methyl (3); Chlopyriphos (3); Cyanofenphos (3); Dyfoxon (1); EPN (1); Ethion (1); Ethoprophos (1); Fensulfothion (3); Isoxathion (1); Parathion (3); Parathion-methyl (3);

Phorate (3); Phosalone (1); Profenofos (1); Prothiofos (3); Tokuoxon (3)

Group 5: $\quad$ Carbophenothion (3); Diazinon (3); Dimethoate (3); Fenthion (3); Malathion (3); Mephosfolan (1); Methidathion (3); Phenthoate (1); Phosmet (3); Pirimiphos-methyl (3); Pyraclofos (1); Pyridaphenthion (1); Quinalphos (3); Triazophos (3)

Group 6: $\quad$ Acephate (3); Bromophos-ethyl (3); Demeton-S-methyl (3); Dichlorvos (3); Fenitrothion (3); Fonofos (3); Methamidophos (3); Mevinphos (3); Monocrotophos (3); Omethoate (3); Terbufos (1)

Synthetic Pyrethroids: 16

Group 7: $\quad$ Allethrin (3); Bifenthrin (3); Fenpropathrin (1); Flucythrinate (1); Tetramethrin (1)

Group 8: $\quad$ Cyhalothrin (1); alpha-Cypermethrin (1); beta-Cyfluthrin (1); Esfenvalerate (1); Tralomrthrin (2)

Group 9: $\quad$ Cyfluthrin (1); Cypermethrin (3); Deltamethrin (3); Fenvalerate (3); Fluvalinate (1); Permethrin (3)

a 1: Dr. Ehrenstorfer GmbH; 2: Merck; 3: Riedel-deHaen. 


\subsection{Reagents}

All reagents were of analytical grade unless otherwise mentioned. Acetone, acetonitrile (isocratic grade for chromatography), anhydrous sodium, magnesium, methanol (gradient grade for chromatography) and $n$-hexane (for organic trace analysis) were purchased from Merck. Post column derivative reagents, including $o$-phthalaldehyde (chromatographic grade, Part. No. O120), o-phthalaldehyde diluent (chromatographic grade, Cat. No. CB910) and thiofluor (chromatographic grade, Cat. No. 3700-2000), were purchased from Pickering Laboratories. Two types of solid phase extraction cartridges: $\mathrm{C} 18$ cartridge $(6 \mathrm{~mL}, 1000 \mathrm{mg})$ and aminopropyl cartridge $(6 \mathrm{~mL}, 1000 \mathrm{mg})$, were purchased from J\&T Baker and Merck, separately. DB-608 capillary column $(0.53 \mathrm{~mm}$ i.d. $\times 30 \mathrm{~m}, 0.83 \mu \mathrm{m})$ was purchased from $\mathrm{J} \& \mathrm{~W}$. Carbamate analysis column $\left(\mathrm{C}_{18} 4.6 \times 250 \mathrm{~mm}\right.$ column, $5 \mu \mathrm{m}$ ) was purchased from Pickering Laboratories (Part Nos. 1846250 \& 1700-0063).

\subsection{Instrument}

The GC (HP Model 6890) system consisted of ${ }^{63} \mathrm{Ni}$ electron capture detector (ECD) and flame photometric detector (FPD). The HPLC (Agilent 1100 series) system consisted of post-column derivatizer (Pickering Laboratories PCX 5200) and fluorescence detector (HP1100 Series). The other apparatuses include Homogenizer (Kinematica, polytron ${ }^{\circledR}$ ), solid phase extraction vacuum manifold and accessories device (J\&W Scientific, SPE), rotary vacuum evaporator (Heidolph model VV2011), aspirator (EYELA A-3S; FHETO SUE 300Q), refrigerated bath circulator (YIH DER BL-710) and nitrogen gas generator (NITROX, UHP0551).

\subsection{Instrument condition}

For OC, OP and pyrethroids pesticides analysis, the instrument conditions were the same as Sun et al.'s method (2003). For carbamate pesticides analysis, HPLC was used. The injection volume was $50 \mu \mathrm{l}$. Mobile phase was combined water (solvent A) with acetonitrile (solvent B) and run with linear gradient, which $A / B=$ $80 / 20(\mathrm{v} / \mathrm{v})$ at time 0 to $A / B=30 / 70$ at $35 \mathrm{~min}$ and then equilibrated at initial conditions for $3 \mathrm{~min}$, its flow rate was $1 \mathrm{ml} / \mathrm{min}$. Analytical column temperature was $40{ }^{\circ} \mathrm{C}$. Catalytic reactor temperature was ca. $100^{\circ} \mathrm{C}$. OPA-reagent flow rate of derivatization was $0.3 \mathrm{ml} /$ min. Excitation wavelength and emission wavelength of detection were $330 \mathrm{~nm}$ and $465 \mathrm{~nm}$, separately.

\subsection{Sample collection}

In reflection upon seafood buying habit of Taiwanese, samples were procured from retail of traditional market, nationwide supermarket, regional supermarket and fish market, or directly from fish farm, during the years of 2001 through 2003 from three major urban areas of Taiwan. They are Taipei, Taichung and Kaohsiung cities.

\subsection{Residue determination}

Each fisheries product was prepared according Pesticide Analytic Manual (FDA, 1994). The cleanup and extraction procedure was modified from Sun et al.'s method (Sun et al., 2000) and briefly described in Fig. 1. All the results had been corrected for percent recovery of the individual pesticides.

The estimation of residue levels in all fisheries samples was according to the guideline of WHO (1997). Maximum residue level was derived from the mean of detected residues. Minimum residue level was derived from the undetected samples which values were regarded as limit of determination/2. Average residue level was derived from all samples including detected and undetected samples.

\subsection{Calculation of estimated daily intake}

For preliminary assessment of consumer's exposure to pesticide residues in fisheries products, the calculated estimated daily intake (EDI) is expressed as percentages of the ADI. The calculations of EDI are described as below:

$$
\begin{aligned}
& \text { EDI }(\mathrm{ng} / \mathrm{kg} \text { body weight/day) } \\
& =\text { seafood consumption }(\mathrm{g} / \mathrm{kg} \text { body weight } / \text { day }) \\
& \quad \times \text { residue }(\mathrm{ng} / \mathrm{g})
\end{aligned}
$$

In this study, seafood consumption data were referred by $\mathrm{Wu}$ et al. (1999). The maximum EDI was derived from the maximum residues.

\section{Results and discussion}

A total of 920 samples of fisheries products were analyzed for pesticide residues from the years 2001 to 2003. Table 2 shows the number of samples surveyed and those containing pesticide residues in each kinds of fisheries product. Overall, $65.40 \%$ of fish, $93.55 \%$ of shellfish, $84.92 \%$ of crustacean and $98.33 \%$ of cephalopod samples contained no detectable residues. There are no detectable residues of carbamate and pyrethroids pesticide in surveyed samples. Organochlorine (OC) pesticide residues are detected in $144(34.60 \%)$ of fish, 4 (6.45\%) shellfish and $28(15.7 \%)$ crustacean samples. Organophosphate (OP) pesticide residues are detected in 69 $(11.37 \%)$ of fish, $2(1.05 \%)$ crustacean and $1(1.67 \%)$ cephalopod samples. Fish had higher detection rates of 


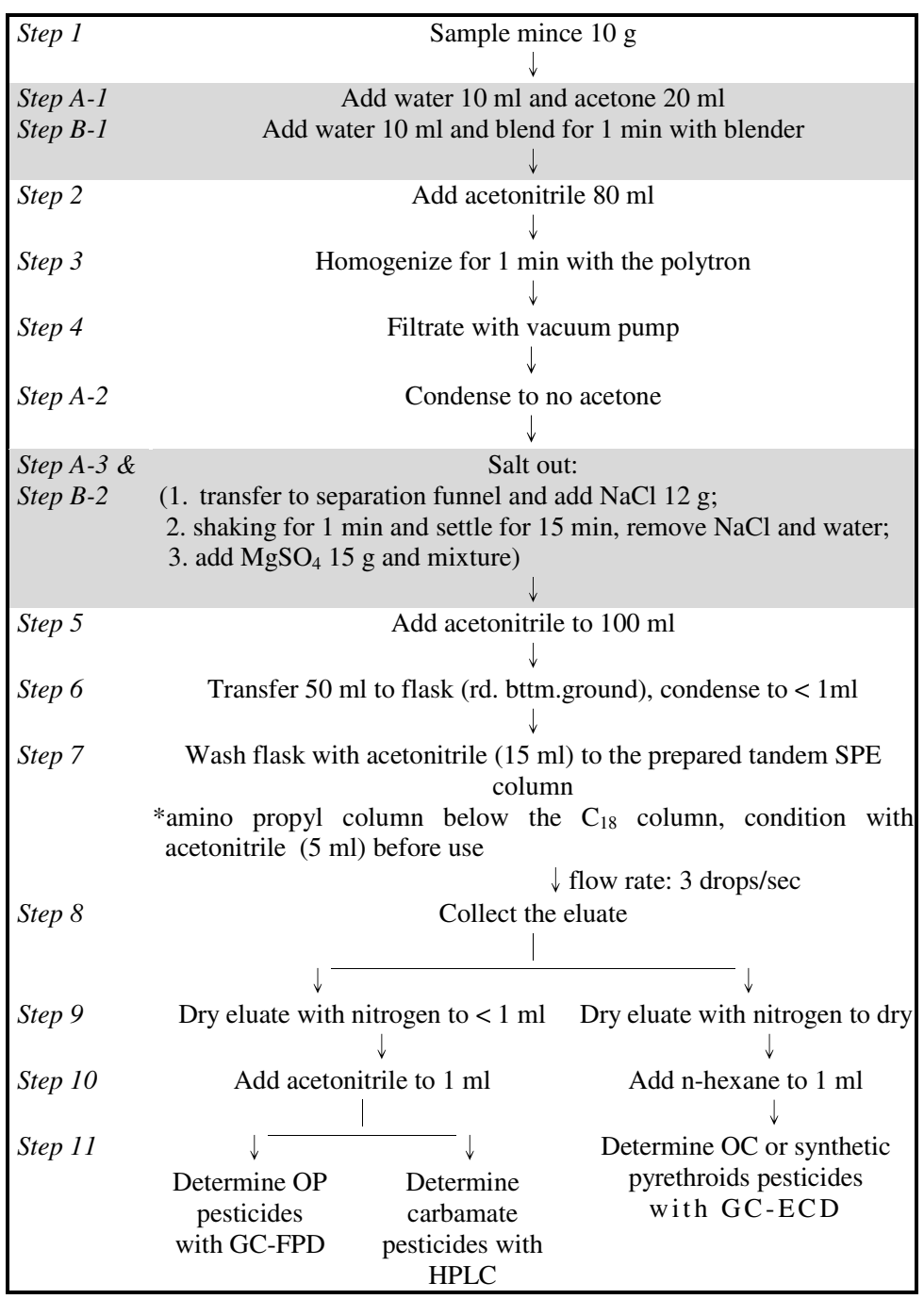

Fig. 1. Analytical procedure for determining pesticide residues in fisheries products. Steps 1-11: for all kinds of fisheries products; Step A: additional procedure for bivalve; Step B: additional procedure for cephalopod.

Table 2

Number of samples surveyed and contained detectable pesticide residues in Taiwan during years of 2001-2003

\begin{tabular}{|c|c|c|c|c|c|c|c|c|}
\hline \multirow[t]{2}{*}{ Seafood } & \multirow{2}{*}{$\begin{array}{l}\text { Surveyed } \\
\text { samples }\end{array}$} & \multirow{2}{*}{$\begin{array}{l}\text { No. of } \\
\text { detected }\end{array}$} & \multirow{2}{*}{$\begin{array}{l}\text { Detection } \\
\text { rates }(\%)\end{array}$} & \multicolumn{4}{|c|}{ Detected of samples } & \multirow{2}{*}{$\begin{array}{l}\text { No. of } \\
\text { multipesticide } \\
\text { residues }\end{array}$} \\
\hline & & & & Carbamate & $\begin{array}{l}\text { Organo- } \\
\text { chlorine }\end{array}$ & $\begin{array}{l}\text { Organo- } \\
\text { phosphate }\end{array}$ & Pyrethroids & \\
\hline Fish & 607 & 210 & 34.60 & 0 & 144 & 69 & 0 & 22 \\
\hline Shellfish & 62 & 4 & 6.45 & 0 & 4 & 0 & 0 & 0 \\
\hline Crustacean & 191 & 30 & 15.71 & 0 & 28 & 2 & 0 & 0 \\
\hline Cephalopod & 60 & 1 & 1.67 & 0 & 0 & 1 & 0 & 0 \\
\hline Total & 920 & 245 & 26.63 & 0 & 176 & 72 & 0 & 22 \\
\hline
\end{tabular}

OC and OP pesticides. These pesticides, however, were not detected in cephalopod or shellfish. Multipesticide residues were detected only in $22(3.62 \%)$ of fish sample.
This result is similar to the no detectable rate of FDA domestic seafood in 1998, 1999 and 2000 separately $(21.50 \%$ in $1998,28.90 \%$ in $1999,24.60 \%$ in 2000$)$ but 
is higher than that in 2001 (18.4\%) (FDA, 1999, 2000, 2002, 2003).

For different fish sources and end user services, pesticides residues detection rates in different selling site are listed and compared in Table 3. The detection rates are greater than $20 \%$ all over the sampling sites. As for the 91 pesticides, DDTs, dieldrin, chlorpyrifos, fenitrotion, fenthion and prothion have been detected from fisheries products. The predominated residues are DDTs (including $p^{\prime} p^{\prime}$-DDD, $p, p^{\prime}$-DDE and $p, p^{\prime}$-DDT). DDT and dieldrin have been banned in 1970s in Taiwan for their long persistence in environment. There are no studies on OC pesticide incidence in product of fish farms in Taiwan so far.

Chlorpyrifos following DDTs is one of the main detectable residues, especially in the nationwide supermarkets (in 30 of sample, 10.07\%) and regional supermarkets (in 29 of sample, 14.08) (Table 3). The next detectable residue is fenitrothion. Chlorpyrifos and fenitrothion are widely used not only in agriculture but also in sanitation in Taiwan. In fisheries products processing, both supermarkets have the highest standards on hygienic conditions. However, in the national supermarkets (nationwide chain store) the service of processing is at sight, whereas in the regional supermarket, the same service is through the central kitchen. Chlorpyrifos is one of the most widely used active ingredients for pest control in the world. Many studies have been conducted in examining critical aspects of chlorpyrifos products as they relate to health and safety (Dishburger et al., 1997; Johnson et al., 1998; Clegg and Gemert, 1999). There are no reports directly pertaining to the contamination of sanitary chemicals on fisheries products. In both kinds of supermarkets, higher multipesticide residues had been detected, in which 9 samples of nation supermarket $(3.02 \%)$ and 12 samples of regional supermarket $(5.83 \%)$ were found.

Table 4 shows data for levels of pesticide residues of all samples. The maximum levels (which derived from the mean of detected residues) of fenthion was as high as $247.60 \mathrm{ng} / \mathrm{g}$, the average values (which derived from all samples including detected and undetected samples) was only $1.06 \mathrm{ng} / \mathrm{g}$ for low detection rate $(0.33 \%)$. Although the residue levels of these pesticides are below the maximum permissible intake (calculate by ADI multiply body weight $60 \mathrm{~kg}$ ) of Codex Committee on Pesticides Residues (CCPR), and some developed countries (Dogheim et al., 1996), there was no zero risk because there were pesticides present in the fish products. In order to take account of the maximum risk of consumer's exposure in fisheries products, the estimated daily intake (EDI) residues was calculated with maximum residue levels.

According to the data from National Nutrition Survey in Taiwan area conducted from 1993 to 1996 (Wu et al., 1999), the mean consumption of seafood

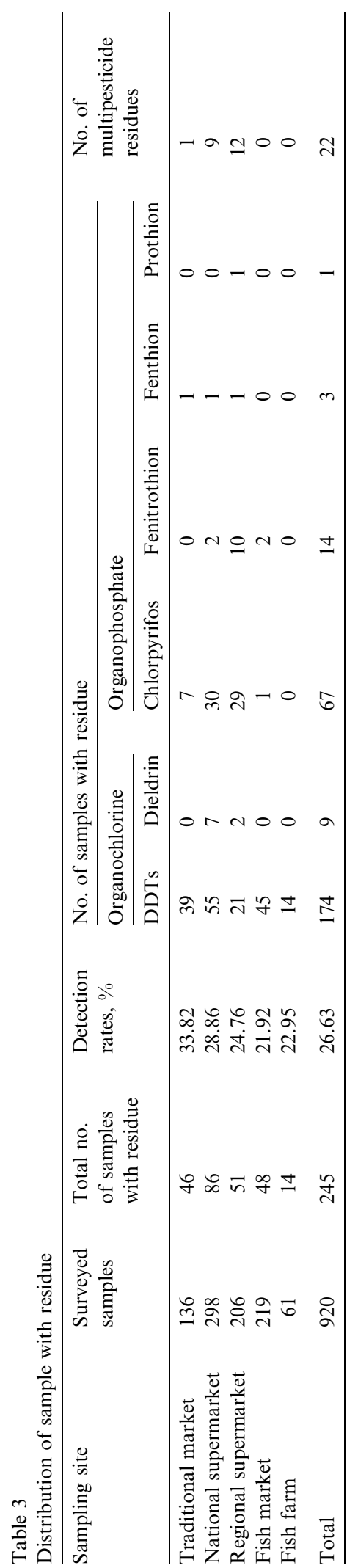


Table 4

Pesticide residues in samples during sampling period (2001-2003)

\begin{tabular}{|c|c|c|c|c|c|}
\hline Pesticide & $\begin{array}{l}\text { Maximum, } \\
\mathrm{ng} / \mathrm{g}\end{array}$ & $\begin{array}{l}\text { Minimum, } \\
\mathrm{ng} / \mathrm{g}\end{array}$ & $\begin{array}{l}\text { Average, } \\
\mathrm{ng} / \mathrm{g}\end{array}$ & $\begin{array}{l}\text { No. of samples } \\
\text { with residue }\end{array}$ & $\begin{array}{l}\text { Detection rate, } \\
\%\end{array}$ \\
\hline \multicolumn{6}{|c|}{ Organochlorine } \\
\hline DDTs & 169.12 & 0.63 & 32.49 & 174 & 18.91 \\
\hline$p, p^{\prime}$-DDD & 80.79 & 0.75 & 13.54 & 147 & 15.98 \\
\hline$p, p^{\prime}-\mathrm{DDE}$ & 40.67 & 0.65 & 8.22 & 174 & 18.91 \\
\hline$p, p^{\prime}-\mathrm{DDT}$ & 68.00 & 0.80 & 12.05 & 154 & 16.74 \\
\hline Dieldrin & 30.68 & 0.64 & 0.93 & 9 & 0.98 \\
\hline \multicolumn{6}{|c|}{ Organophosphate } \\
\hline Chlorpyrifos & 27.89 & 0.26 & 2.27 & 67 & 7.28 \\
\hline Fenitrothion & 55.43 & 0.20 & 1.04 & 14 & 1.52 \\
\hline Fenthion & 247.60 & 0.25 & 1.06 & 3 & 0.33 \\
\hline Prothiofos & 15.25 & 0.29 & 0.30 & 1 & 0.11 \\
\hline
\end{tabular}

Table 5

Estimated dietary intakes (EDIs) of pesticide residues by adults in Taiwan area and acceptable daily intake (ADIs)

\begin{tabular}{|c|c|c|c|c|c|}
\hline \multirow[t]{2}{*}{ Pesticde } & \multicolumn{2}{|c|}{ EDI (ng/kg body weight/day) } & \multicolumn{2}{|c|}{$\mathrm{EDI} \%$ of $\mathrm{ADI}$} & \multirow{2}{*}{$\begin{array}{l}\text { ADI, mg/kg } \\
\text { body weight/day }\end{array}$} \\
\hline & Male & Female & Male & $\overline{\text { Female }}$ & \\
\hline \multicolumn{6}{|c|}{ Organochlorine } \\
\hline DDTs & 257.90 & 194.20 & 1.29 & 0.97 & 0.02 \\
\hline Dieldrin & 46.78 & 35.23 & 93.56 & 70.45 & 0.00005 \\
\hline \multicolumn{6}{|c|}{ Organophosphate } \\
\hline Chlorpyrifos & 42.53 & 32.03 & 0.43 & 0.32 & 0.01 \\
\hline Fenitrothion & 84.53 & 63.65 & 1.69 & 1.27 & 0.005 \\
\hline Fenthion & 377.60 & 284.33 & 5.39 & 4.06 & 0.007 \\
\hline Prothiofos & 23.25 & 17.51 & 23.25 & 17.51 & 0.0001 \\
\hline
\end{tabular}

(including freshwater fish, saltwater fish, shellfish and shellfish products) by males were $91.5 \mathrm{~g}$ and females were $68.9 \mathrm{~g}$. Table 5 shows the results of calculation of preliminary EDIs of pesticides and the corresponding ADIs by adults in Taiwan area. The exposure did not exceed the ADI certainly. For male, there was the highest risk in exposure to dieldrin through consumption of fisheries product, which the percentage of ADI was $93.56 \%$.

It was realized that $\mathrm{OC}$ pesticides are environmentally hazardous and many developed and developing countries have been continuing to monitor the trends of residue concentrations in fish and other biota. But maximum residues limit (MRL) for OC pesticides in seafood are currently not in force in most countries. This study shows that there has been some OP pesticide residue detected in fisheries products. It indicates that the present monitoring program that has been conducted only for OC pesticides in fish is insufficient. Although OP pesticide residues in fisheries products do not pose any immediate risk to human health so far, a yearly monitoring program for OP pesticide residues in fisheries products, especial in fish, is necessity.

The higher multipesticide residues detected in the samples from supermarkets also suggests that the appli- cation procedure of sanitation chemical should be reviewed to prevent chemical contamination in fisheries products.

\section{References}

Clegg, D.J., Gemert, M.V., 1999. Expert panel report of human studies on chlorpyrifos and/or other organophosphate exposures. J. Toxicol. Environ. Health. Part B: Crit. Rev. 2, 257-279.

Dishburger, H.J., McKellar, R.L., Pennington, J.Y., Rice, J.R., 1997. Determination of residues of chlorpyrifos [insecticide], its oxygen analogue, and 3,5,6-trichloro-2-pyridinol in tissues of cattle fed. J. Agric. Food Chem. 25, 1325-1329.

Dogheim, S.M., Mohamed, E.Z., Alla, S.A.G., Elsaied, S., Emel, S.Y., Mohsen, A.M., Fahmy, S.M., 1996. Monitoring of pesticides residues in human milk, soil, water, and food samples collected from Kafr El-Zayat governorate. J. Assoc. Off. Anal. Chem. 79, 111-116.

Fairchild, J.F.L., Point, T.W., Zajicek, J.L., Nelson, M.K., Dwyer, F.J., Lovely, P.A., 1992. Population-, communityand ecosystem-level responses of aquatic mesocosms to pulsed doses of a pyrethroid insecticide. Environ. Toxicol. Chem. 11, 115-129. 
FDA, 1994. Pesticides analytical manual: Vol. 1 Multiresidue method. No. 94-1(1/94) From 2905a (6/92).

FDA, 1999. Food and Drug Administration Pesticide Program: Residue Monitoring 1998, US Food and Drug Administration Center for Food Safety and Applied Nutrition.

FDA, 2000. Food and Drug Administration Pesticide Program: Residue Monitoring 1999, US Food and Drug Administration Center for Food Safety and Applied Nutrition.

FDA, 2002. Food and Drug Administration Pesticide Program: Residue Monitoring 2000, US Food and Drug Administration Center for Food Safety and Applied Nutrition.

FDA, 2003. Food and Drug Administration Pesticide Program: Residue Monitoring 2001, US Food and Drug Administration Center for Food Safety and Applied Nutrition.

Gomez, C.G., Martinez, M.I.A., Palanco, J.L.R., Lucas, I.I.G., Rojas, M.A.V., 1995. Monitoring of organophosphorus insecticides in the Guadalete river (southern Spain). Bull. Environm. Contam. Toxicol. 55, 431-438.

Gupta, R.C., 1994. Carbofuran toxicity. J. Toxicol. Environ. Health 43, 383-418.

Hanazato, T., 1991. Effects of long- and short-term exposure to carbaryl on surrival, growth and reproduction of Daphnia magnia. Environ. Pollut. 74, 139-148.

Johnson, D.E., Seidler, F.J., Slotkin, T.A., 1998. Early biochemical detection of delayed neurotoxicity resulting from developmental exposure to chlorpyrifos. Brain Res. Bull. 45, 143-147.

Keith, L.H., 1998. Environmental endocrine disruptors. Pure Appl. Chem. 70, 2319-2326.

Lenardon, A.M., de Hevia, M.I.M., Fuse, J.A., de Nochetto, C.B., Depetris, P.J., 1984. Organochlorine and organophosphorous pesticides in the Parana River (Argentina). Sci. Total Environ. 34, 289-297.

Li, G.C., 2000, Agricultural chemicals regulation and risk assessment in Taiwan IUPAC-TACTRI/COA International Workshop on Pesticides 2000 Proceedings, pp. 42-48.

Ling, Y.C., Huang, I.P., 1995. Multiresidue-matrix solid-phase dispersion method for determining 16 organochlorine pesticides and polychlorinated biphenyls in fish. Chromatogra 40, 259-266.
Lutnicka, H., Bogacka, T., Wolska, L., 1999. Degradation of pyrethroids in an aquatic ecosystem model. Water Res. 33, 3441-3446.

Neidermyer, W.J., Hickey, J.J., 1976. Chronology of organochlorine compounds in Lake Michigan fish, 1929-66. Pestic. Monit. J. 10, 92-99.

Saglio, P., Trijasse, S., Azam, D., 1996. Behavioral effects of waterborne carbofuran in goldfish. Arch. Environ. Contam. Toxicol. 31, 232-238.

Serrano, R., Hernandez, H., Pena, J.B., Dosda, V., Canales, J., 1995. Toxicity and bioconcentration of selected organophosphorus pesticides in Mytilus galloprovincialis and Venus gallina. Arch. Environ. Contam. Toxicol. 29, 284-290.

Singh, R.K., Sharma, B., 1998. Carbofuran-induced biochemical changes in Clarias batrachus. Pestic. Sci. 53, 285-290.

Sreenivasula, R.P., 1992. Fenitrothion-induced alterations in ammonia metabolis in the crab, Oziotelphusa senex senex Fabricius. Pestic. Sci. 35, 249-254.

Sreenivasula, R.P., Bhagyalakshmi, A., Ramamurthi, R., 1983. Effect of sublethal concentrations of sumithion on limb regeneration of fresh water field crab Oziotelphusa senex senex (organophosphorus pesticide). Experientia 39, 13801381.

Sun, F., Lin, F.Y., Wong, S.S., Li, G.C., 2000. Determination of organochlorine and nitrogen-containing pesticide residues in fish with different fat content. J. Food Drug Anal. 8, 103-111.

Sun, F., Lin, F.Y., Wong, S.S., Li, G.C., 2003. The screen of organophosphorus, organochlorine and synthetic pyrethroid pesticide residues in beef fat by tandem solid-phase extraction technique. J. Food Drug Anal. 11, 258-265.

WHO, 1997. Guidelines for predicting dietary intake of pesticide residues (revised) pre-pared by the Global Environment Monitoring System-Food Contamination Monitoring and Assessment Programme (GEMS/Food) in collaboration with Codex Committee on Pesticide Residues, WHO/FSF/FOS/97.7.

Wu, S.J., Chang, Y.H., Fang, C.W., Pan, W.-H., 1999. Food sources of weight, calories, and three macro-nutrientsNAHSIT 1993-1996. Nutr. Sci. J. 24, 41-58. 